\title{
POLÍTICA E GESTÃO EDUCACIONAL NA LICENCIATURA: BIBLIOGRAFIA BÁSICA E CONTEÚDO
}

\author{
Selma dos Santos ${ }^{1}$
}

\section{RESUMO}

O presente artigo busca responder o questionamento: por que estudar Política e Gestão Educacional nos cursos de licenciatura? Tem como objeto de estudo o campo das políticas públicas e da gestão educacional e escolar, as relações entre Estado, sociedade, direito e educação. Os objetivos são apresentar uma fundamentação teórica para embasamento do estudo de Política e Gestão Educacional na Licenciatura através de quadros compostos pelas chaves: autor, ano da publicação, palavras-chave e síntese do conteúdo. E, discutir por que estudar Política e Gestão Educacional na licenciatura: exemplificando com as Ciências Biológicas. O resultado é uma proposta de planejamento de ensino com atividades de exposição dialogada, leitura crítica dos textos e da realidade, debate, roda de conversa, caça tesouro, júri simulado, simpósio, mesa redonda, oficina pedagógica. Conclui com a pergunta: qual é o meu papel de cidadão na vida política e pública na sociedade?

Palavras-chave: Políticas públicas. Gestão educacional e escolar. Licenciatura. Conteúdo de ensino.

\begin{abstract}
This article seeks to answer the question: why study Educational Policy and Management in licentiate degree courses? Its object is to study the field of public policies and educational and scholastic management, relations between State, society, law and education. The objectives are to present a theoretical basis to support the study of Educational Policy and Management in the Licentiate degree through tables composed of the keys: author, year of publication, keyword and content synthesis. And, discuss why study Educational Policy and Management in the licentiate degree course: as an example with the Biological Sciences. The result is a proposal of teaching planning with activities of dialogued exhibition, critical reading of texts and reality, debate, table talk, treasure hunting, simulated jury, symposium, roundtable, pedagogical workshop. It concludes with the question: what is my role as a citizen in political and public life in society?
\end{abstract}

Keywords: Public policy. Educational and school management. Licentiate. Teaching content.

\footnotetext{
${ }^{1}$ Doutoranda em Educação e Contemporaneidade pela Universidade Estadual da Bahia (UNEB). Mestre em Educação em Pesquisa - Université Du Quebéc à Chicoutimi. Graduação em Licenciatura Plena em Estudos Sociais pela Universidade Estadual de Feira de Santana (UEFS). Especialização em A Formação do Professor Alfabetizador: Leitura e Linguagem (UEFS). Professora da Universidade Estadual de Feira de Santana (UEFS)
} 


\section{Introdução}

Geralmente os cursos de licenciatura trazem em sua matriz curricular um componente que trata da política e da gestão educacional. Muitos estudantes não percebem a importância de aprender sobre política, política educacional, a legislação, o financiamento da educação e sobre a gestão educacional e escolar. Questionam, quase sempre, por que estudar Política e Gestão Educacional nos cursos de licenciatura? A inquietação provocada por está questão nos leva a apontar aos leitores como objeto de estudo o campo das políticas públicas e da gestão educacional e escolar, as relações entre Estado, sociedade, direito e educação. Os objetivos são apresentar uma fundamentação teórica para embasamento do estudo de Política e Gestão Educacional na licenciatura através de quadros compostos pelas chaves: autor, ano da publicação, palavras-chave e síntese do conteúdo. E, discutir por que estudar Política e Gestão Educacional na licenciatura: exemplificando com as Ciências Biológicas. A metodologia dar-se através de uma breve revisão bibliográfica de artigos publicados em periódicos nacionais a partir de 2000 e da indicação de alguns livros.

\section{Conceituando o campo da Política Pública e da Gestão Educacional}

O campo de conhecimento das políticas públicas é considerado por Souza (2003, p. 13) como "um campo holístico, isto é, uma área que abrange diversas unidades em totalidades organizadas", o que o torna território de várias disciplinas, teorias e modelos analíticos, ao mesmo tempo em que "comporta vários 'olhares' sem que esta multiplicidade de perspectivas comprometa a sua coerência teórica e metodológica" (SOUZA, 2003, p. 14).

[...] Portanto, pensando as políticas públicas como conjunto de ações sistemáticas para sanear problemas que afetam a vida de grupos sociais específicos ou de coletividades mais amplas, propõe-se o protagonismo do Estado como espaço de disputa de projetos marcados por correlações de forças nem sempre contínuas (SILVA; SCAFF; JACOMINI, 2010). (SILVA; JACOMINI, 2016, p. 47)

Assim, "a política educacional é então focalizada como política voltada aos processos participativos, e que, dentre outras coisas, deveria ser alvo de controle social, daí a importância atribuída à avaliação." (SANTOS; AZEVEDO, 2014, p. 70).

Por outro lado, falando de gestão, para Souza (2008) os estudos sobre gestão contribuem para dar maior visibilidade aos problemas da gestão escolar/educacional. Para 
ele "A gestão educacional não tem um campo de conhecimento próprio e não parece ruim que não o tenha, pois ela é uma espécie de amálgama de conhecimentos que advêm de campos um tanto diversos, como a política e a educação" (p. 58).

A leitura de Saviani (2008) colabora para o entendimento conceitual de educação, estabelecendo à especificidade da educação a partir de uma concepção histórico-crítica, situando a educação como trabalho não material e a Pedagogia como ciência que a toma como objeto. Charlot (2006) também problematizou as especificidades e os desafios da educação como área de conhecimento, argumenta que "A educação é um triplo processo de humanização, socialização e entrada numa cultura, singuralização-subjetivação. Educa-se um ser humano, o membro de uma sociedade e de uma cultura, um sujeito singular" (CHARLOT, 2006, p. 15). (SILVA; JACOMINI, 2016).

Para seguir o estudo do campo da política educacional é preciso ter clareza conceitual de educação. Assim, abaixo segue alguns conceitos com propósito de ajudar a pensar o objeto de estudo educação.

[...] Educação é um fenômeno próprio dos seres humanos significa afirmar que ela é, ao mesmo tempo, uma exigência do e para o processo de trabalho, bem como é, ela própria, um processo de trabalho. [...] (SAVIANI, 2008)

[...] A educação, enquanto atividade intencionalizada, é uma prática social cunhada como influência do meio social sobre o desenvolvimento dos indivíduos na sua relação ativa com o meio natural e social, tendo em vista, precisamente, potencializar essa atividade humana para torna-la mais rica, mais produtiva, mais eficaz diante das tarefas da práxis social postas num dado sistema de relações sociais. [...] (LIBÂNEO, 2010, p. 82)

Na legislação brasileira atual, a educação é entendida como "os processos formativos que se desenvolvem na vida familiar, na convivência humana, no trabalho, nas instituições de ensino, pesquisa e extensão, nos movimentos sociais e organizações da sociedade civil e nas relações criativas entre natureza e cultura". (Resolução $n^{\circ} 2$, de $1^{\circ}$ de julho de 2015 , artigo $\left.3^{\circ}, \S^{\circ}\right)$.

E, a função da escola é de munir de conhecimento o sujeito dentro de um sistema de progressão escolar com intenção de responder às demandas produtivas do presente contexto social. (SANTOS et al., 2016, p. 12)

A educação escolar, é uma instância de educação formal, não pode eximirse da interação com outras modalidades de educação (informal e nãoformal). E, em seu caráter específico dedica-se à instrução e ao ensino, para isso convergindo sua organização interna, sua diferenciação por graus, 
seus procedimentos específicos, há que se ver que a educação escolar assume atributos que a aproximam de outras instituições e atividades fora de seu marco próprio. Essa constatação põe a exigência de que os objetivos, os conteúdos, os métodos se abram para relações mais amplas entre o indivíduo e o meio humano, social, físico, ecológico, cultural, econômico, não é o caso de minimizar seu papel na transmissão e assimilação ativa dos saberes, mas de diversificar suas formas de atuação. Isso implica maior interação entre a instituição escolar e comunidade local, regional, nacional, ligando o mundo exterior ao cotidiano escolar tornando mais eficaz sua própria contribuição ao mundo exterior pelo desempenho de suas tarefas específicas. (LIBÂNEO, 2010, p. 97-98)

\section{Fundamentação teórica para embasamento do estudo de Política e Gestão Educacional na Licenciatura}

Para a execução do trabalho escolar, é necessário a ação do docente. . (SANTOS et al., 2016, p. 12)

Compreende-se a docência como ação educativa e como processo pedagógico intencional e metódico, envolvendo conhecimentos específicos, interdisciplinares e pedagógicos, conceitos, princípios e objetivos da formação que se desenvolvem na construção e apropriação dos valores éticos, linguísticos, estéticos e políticos do conhecimento inerentes à sólida formação científica e cultural do ensinar/aprender, à socialização e construção de conhecimentos e sua inovação, em diálogo constante entre diferentes visões de mundo. (Resolução $\mathrm{n}^{\circ} 2$, de $1^{\circ}$ de julho de 2015, artigo $\left.2^{\circ}, \S 1^{\circ}\right)$

Com a compreensão do papel da docência passamos a compreensão do que constitui o arcabouço do ser professor na formação inicial sobre política e gestão educacional. Assim, apresentamos os quadros com sínteses de estudos na área.

\section{Quadro 01- Estado, sociedade, direito e educação.}

\begin{tabular}{|l|l|lr|l|}
\hline AUTOR & ANO & PALAVRAS-CHAVE & SINTESE DO CONTEÚDO \\
\hline $\begin{array}{l}\text { Alves; } \\
\text { Batista; }\end{array}$ & 2015 & $\begin{array}{l}\text { Escolas } \\
\text { Ribeiro; } \\
\text { Érnica. }\end{array}$ & $\begin{array}{l}\text { Política de regulação. } \\
\text { Processos e práticas de } \\
\text { regulação. Disciplina. }\end{array}$ & $\begin{array}{l}\text { Processos e práticas utilizadas por escolas } \\
\text { públicas no contexto de regulação de } \\
\text { escolhas: matrículas, o evitamento, a } \\
\text { expulsão velada. Trata dos processos de } \\
\text { expulsão (convite, pressão à família, } \\
\text { negação da vaga, os pedidos). Princípio } \\
\text { gerador das práticas e processos de seleção } \\
\text { reside na busca de assegurar um ambiente } \\
\text { escolar disciplinado. }\end{array}$ \\
\hline $\begin{array}{l}\text { Santos; } \\
\text { Azevedo. }\end{array}$ & 2014 & $\begin{array}{l}\text { Estado. } \\
\text { educacional. } \\
\text { GT 05. Produção. }\end{array}$ & $\begin{array}{l}\text { Política } \\
\text { EPENN.enta o estado da arte de maneira } \\
\text { descritiva e analítica da produção de } \\
\text { conhecimento do GT 05 Estado e Política }\end{array}$ \\
\hline
\end{tabular}




\begin{tabular}{|c|c|c|c|}
\hline AUTOR & ANO & PALAVRAS-CHAVE & SINTESE DO CONTEÚDO \\
\hline & & & $\begin{array}{l}\text { Educacional divulgada durante os } \\
\text { Encontros de Pesquisa em Educação do } \\
\text { Norte e Nordeste (EPENN), do período de } \\
1999 \text { a } 2011 \text {. }\end{array}$ \\
\hline Lima & 2008 & $\begin{array}{l}\text { Estado. Escola. } \\
\text { Família. Controle social. }\end{array}$ & $\begin{array}{l}\text { Trata do dever, do direito de escolha e da } \\
\text { responsabilização sobre a educação, } \\
\text { problematizando o papel da família e a } \\
\text { função do Estado. A relação entre a família, } \\
\text { a escola e a sociedade resulta em um } \\
\text { modelo de política educacional. }\end{array}$ \\
\hline Barroso & 2005 & 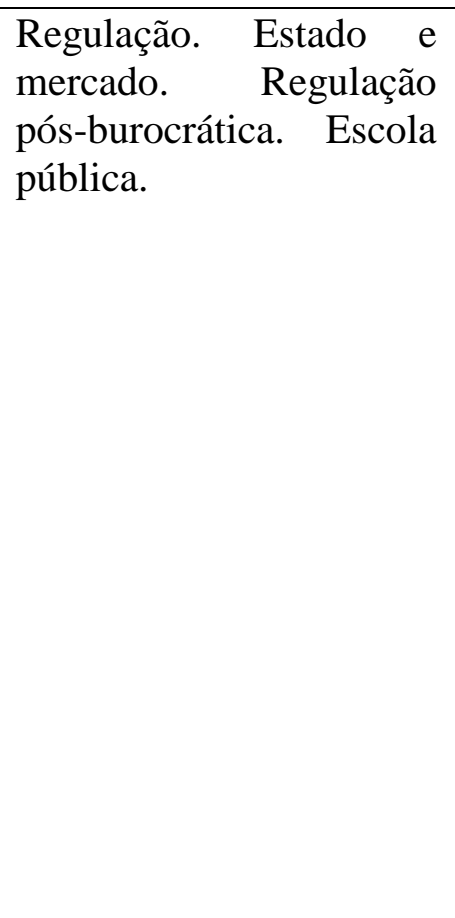 & $\begin{array}{l}\text { Analisa e debate a evolução da intervenção } \\
\text { do Estado na educação no quadro das } \\
\text { transformações que ocorrem, em diferentes } \\
\text { países, na regulação das políticas e da ação } \\
\text { pública. Partindo da elucidação do conceito } \\
\text { de regulação, apresenta um modelo } \\
\text { interpretativo para análise dos processos de } \\
\text { regulação em educação, identificando as } \\
\text { principais convergências e divergências que } \\
\text { se verificam, em alguns países europeus, } \\
\text { neste domínio, nomeadamente no que se } \\
\text { refere à emergência de modelos de } \\
\text { regulação pós-burocráticos. A parte final do } \\
\text { artigo é consagrada à discussão do papel do } \\
\text { Estado na defesa e promoção da escola } \\
\text { pública, tendo em conta as evoluções que } \\
\text { foram detectadas nos modos de governação } \\
\text { e coordenação das políticas e da ação } \\
\text { públicas em educação. }\end{array}$ \\
\hline Cury & 2008 & $\begin{array}{l}\text { Educação básica. Direito } \\
\text { à educação. Ensino } \\
\text { obrigatório. LDB-BR } \\
\text { [conceito fundamental]. }\end{array}$ & $\begin{array}{l}\text { Colabora com o conceito de educação } \\
\text { básica que aparece na Lei de Diretrizes e } \\
\text { Bases da Educação Nacional. Como direito, } \\
\text { a educação básica se impõe como uma } \\
\text { ampliação do espectro da cidadania } \\
\text { educacional. Suas decorrências para a } \\
\text { organização da educação nacional. }\end{array}$ \\
\hline Charlot & 2006 & $\begin{array}{l}\text { Educação. Ciências da } \\
\text { educação. Pesquisa em } \\
\text { educação. }\end{array}$ & $\begin{array}{l}\text { A educação é produzida intencionalmente e } \\
\text { o processo de ensino-aprendizagem se } \\
\text { ancora no triplo movimento de } \\
\text { humanização, socialização e entrada na } \\
\text { cultura. No artigo o autor problematiza } \\
\text { sobre a produção de conhecimento em } \\
\text { educação e a saturação dos discursos } \\
\text { sobre/na área. }\end{array}$ \\
\hline Mitter & 2002 & $\begin{array}{l}\text { Globalização. Educação. } \\
\text { Escola. }\end{array}$ & $\begin{array}{l}\text { A educação no Processo de Globalização: } \\
\text { algumas considerações sobre um debate } \\
\text { atual e controverso. }\end{array}$ \\
\hline Davies & 2006 & 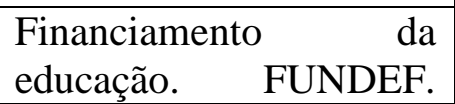 & 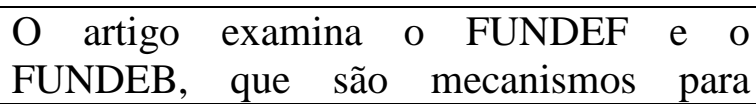 \\
\hline
\end{tabular}




\begin{tabular}{|c|c|c|c|}
\hline AUTOR & ANO & PALAVRAS-CHAVE & SINTESE DO CONTEÚDO \\
\hline & & FUNDEB. & $\begin{array}{l}\text { redistribuir, dentro de cada estado, entre o } \\
\text { governo estadual e as prefeituras, uma parte } \\
\text { dos impostos (15\% de alguns, no caso do } \\
\text { FUNDEF, e } 20 \% \text { de um número maior de } \\
\text { impostos, no caso do FUNDEB) já } \\
\text { vinculados à manutenção } \\
\text { desenvolvimento do ensino pela } \\
\text { Constituição Federal de 1988, com base no } \\
\text { número de matrículas no ensino } \\
\text { fundamental regular (o FUNDEF) e na } \\
\text { educação básica (o FUNDEB). Enfatiza } \\
\text { algumas das deficiências dos dois fundos. }\end{array}$ \\
\hline Cavalcante & 2002 & $\begin{array}{lr}\text { Ensino } & \text { público. } \\
\text { Financiamento. } & \text { Ensino } \\
\text { médio. Distrito Federal. }\end{array}$ & $\begin{array}{l}\text { O artigo tem como objetivo estimar os } \\
\text { custos indiretos do ensino médio para os } \\
\text { alunos das escolas públicas do Distrito } \\
\text { Federal, com suas implicações para a } \\
\text { democratização do ensino médio. } \\
\text { Utilizaram-se os critérios de "precificação" } \\
\text { oriundos da contabilidade, da Matemática } \\
\text { Financeira, da Estatística, da Economia e da } \\
\text { Administração Financeira. Os resultados } \\
\text { encontrados são conclusivos que os alunos } \\
\text { de modestos poder aquisitivos recebem } \\
\text { discriminações sutis no processo de } \\
\text { formação e os conhecimentos adquiridos } \\
\text { ficam aquém das expectativas de posições } \\
\text { profissionais de comando. } \\
\text { O autor propõe intervenções com políticas } \\
\text { públicas que garantam acesso e } \\
\text { permanência dos estudantes na escola. }\end{array}$ \\
\hline Vieira & 2001 & $\begin{array}{l}\text { Política Social e } \\
\text { Cidadania. Sociedade. } \\
\text { Estado e Direito. Direito } \\
\text { e Educação. Cidadania e } \\
\text { Educação. }\end{array}$ & $\begin{array}{l}\text { Trabalha a relação entre sociedade, Estado } \\
\text { e direito, tem como elemento mediador a } \\
\text { educação. Inicialmente, faz-se a exposição } \\
\text { dos momentos distintos e marcantes da } \\
\text { política social no século XX no Brasil: o } \\
\text { primeiro período: a política social como } \\
\text { controle da política (1930-1954); o segundo } \\
\text { período: a política social como política de } \\
\text { controle (1964-1988); o terceiro período: a } \\
\text { política social sem direitos sociais (depois } \\
\text { de 1988). Em seguida, passam-se por } \\
\text { exame as ideias de sociedade civil; de } \\
\text { cidadania; de direitos civis, políticos e } \\
\text { sociais; caracterizando o chamado estado de } \\
\text { direito democrático e indicando alguns } \\
\text { elementos básicos da democracia. A } \\
\text { Constituição Federal de } 1988 \text { consagra o } \\
\text { estado de direito democrático e explicita a } \\
\text { política educacional a ser implementada no }\end{array}$ \\
\hline
\end{tabular}




\begin{tabular}{|c|c|c|c|}
\hline AUTOR & ANO & PALAVRAS-CHAVE & SINTESE DO CONTEÚDO \\
\hline & & & $\begin{array}{l}\text { Brasil. Há demonstração de que o Direito } \\
\text { Educacional não se limita à simples } \\
\text { exposição da legislação do ensino, pois a } \\
\text { educação é um bem jurídico, individual e } \\
\text { coletivo, embora as determinações } \\
\text { constitucionais nem sempre sejam } \\
\text { cumpridas. }\end{array}$ \\
\hline Hofling & 2001 & $\begin{array}{l}\text { Estado e política social. } \\
\text { Políticas públicas e } \\
\text { educação. } \\
\text { Educacional. }\end{array}$ & $\begin{array}{l}\text { Objetiva trazer elementos que contribuam } \\
\text { para a compreensão da relação sociedade, } \\
\text { Estado, política educacional, enfocando } \\
\text { autores que se aproximam da abordagem } \\
\text { marxista e da neoliberal sobre o tema } \\
\text { gestão democrática na escola e o direito à } \\
\text { educação. }\end{array}$ \\
\hline $\begin{array}{l}\text { Freire } \\
\text { (livro) }\end{array}$ & 2001 & Política. Educação. & $\begin{array}{l}\text { Ideia central: a reflexão político-pedagógica } \\
\text { Sumário: Educação permanente e as } \\
\text { cidades educativas. Educação de adultos, } \\
\text { hoje. Algumas reflexões. Anotações sobre } \\
\text { unidade na diversidade. Educação e } \\
\text { qualidade. Alfabetização como elemento de } \\
\text { formação da cidadania. Do direito de } \\
\text { criticar - do dever de não mentir, ao } \\
\text { criticar. Educação e participação } \\
\text { comunitária. Ninguém nasce feito: é } \\
\text { experimentando-nos no mundo que nós nos } \\
\text { fazemos. Educação e responsabilidade. } \\
\text { Educação pública e educação popular. } \\
\text { Universidade católica - reflexões em torno } \\
\text { de suas tarefas. }\end{array}$ \\
\hline Brasil & 2015 & $\begin{array}{l}\text { Resolução } \mathrm{n}^{\circ} 2 \text {, de } 1^{\circ} \text { de } \\
\text { julho de } 2015 \text {. }\end{array}$ & $\begin{array}{l}\text { Define as Diretrizes Curriculares Nacionais } \\
\text { para a formação inicial em nível superior } \\
\text { (cursos de licenciatura, cursos de formação } \\
\text { pedagógica para graduados e cursos de } \\
\text { segunda licenciatura) e para a formação } \\
\text { continuada. }\end{array}$ \\
\hline
\end{tabular}

Fonte: SANTOS, 2017.

Quadro 02 - Política educacional

\begin{tabular}{|l|l|l|l|}
\hline AUTOR & ANO & PALAVRAS-CHAVE & \multicolumn{1}{c|}{ SINTESE DO CONTEÚDO } \\
\hline Souza & 2016 & $\begin{array}{l}\text { Políticas educacionais. } \\
\text { Pesquisa Educacional. } \\
\text { Estado. Epistemologia. }\end{array}$ & $\begin{array}{l}\text { Apresenta os objetos de estudo da política } \\
\text { educacional, conduzindo à conclusão que o } \\
\text { campo de pesquisa em questão trata da } \\
\text { relação entre demanda social por educação e } \\
\text { o posicionamento do Estado diante desta } \\
\text { demanda, com todas as decorrências deste } \\
\text { movimento, especialmente às atinentes à } \\
\text { disputa pelo poder e suas relações com o } \\
\text { universo da educação. }\end{array}$ \\
\hline
\end{tabular}




\begin{tabular}{|c|c|c|c|}
\hline Weber & 2015 & $\begin{array}{l}\text { Valorização docente. } \\
\text { Formação docente. } \\
\text { Políticas educacionais. } \\
\text { Qualidade da educação. } \\
\text { PNE. }\end{array}$ & $\begin{array}{l}\text { Apresenta ângulos do debate sobre a } \\
\text { valorização docente. Retraça sentidos que } \\
\text { foram se fixando nas políticas educacionais } \\
\text { estabelecidas nos últimos } 40 \text { anos no } \\
\text { contexto da luta em favor da democracia. }\end{array}$ \\
\hline Oliveira & 2010 & $\begin{array}{ll}\text { Política. } & \text { Pública. } \\
\text { Políticas } & \text { públicas } \\
\text { educacionais. } & \\
\text { Globalização. } & \\
\text { Neoliberalismo. } & \end{array}$ & $\begin{array}{l}\text { Conceitua política, pública, políticas públicas } \\
\text { educacionais. Tipos de políticas públicas são } \\
\text { exemplificados. Usa o estudo de Souza } \\
\text { (2003) para trazer as definições de políticas } \\
\text { públicas. }\end{array}$ \\
\hline Saviani & $2008 \mathrm{a}$ & $\begin{array}{l}\text { Educação Brasileira. } \\
\text { Educação Pública. } \\
\text { Política Educacional. } \\
\text { Políticas Sociais e } \\
\text { Política Educacional. }\end{array}$ & $\begin{array}{l}\text { Em "política educacional brasileira: limites e } \\
\text { perspectivas" aborda a descontinuidade das } \\
\text { medidas educacionais acionadas pelo Estado, } \\
\text { da escassez dos recursos financeiros } \\
\text { destinados à educação; as intermináveis } \\
\text { reformas. Traz como perspectivas o Plano de } \\
\text { Desenvolvimento da Educação (PDE). }\end{array}$ \\
\hline Souza & 2006 & 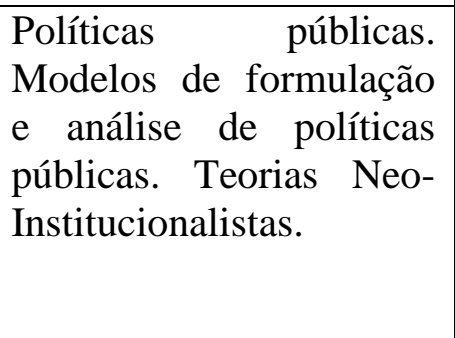 & $\begin{array}{l}\text { Políticas Públicas: uma revisão da literatura. } \\
\text { Principais conceitos e modelos de } \\
\text { formulação e análise de políticas públicas, } \\
\text { buscando sintetizar o estado-da-arte da área. } \\
\text { As possibilidades aplicativas das diferentes } \\
\text { vertentes das teorias neo-institucionalistas à } \\
\text { análise de políticas públicas. }\end{array}$ \\
\hline
\end{tabular}

Fonte: SANTOS, 2017.

\section{Quadro 03 - Gestão educacional e gestão escolar}

\begin{tabular}{|l|l|l|l|}
\hline AUTOR & ANO & PALAVRAS-CHAVE & SINTESE DO CONTEÚDO \\
\hline Azevedo & 2017 & $\begin{array}{l}\text { Projeto político- } \\
\text { pedagógico } \\
\text { Contexto. Gestão escolar. } \\
\text { Democratização. } \\
\text { Participação. }\end{array}$ & $\begin{array}{l}\text { O princípio de gestão democrática e a } \\
\text { participação da comunidade escolar na } \\
\text { elaboração do PPP - Projeto político } \\
\text { pedagógico. }\end{array}$ \\
\hline Souza & 2008 & $\begin{array}{l}\text { Gestão educacional. } \\
\text { Gestão escolar. Ensino em } \\
\text { gestão } \\
\text { educacional/escolar. }\end{array}$ & $\begin{array}{l}\text { Discute conhecimentos no campo da gestão } \\
\text { educacional, apresentando pontos de vista } \\
\text { sobre a (in)existência de um corpo teórico } \\
\text { próprio no campo. }\end{array}$ \\
\hline Cury & 2007 & $\begin{array}{l}\text { Direito à educação. } \\
\text { Gestão democrática. } \\
\text { Legislação educacional. } \\
\text { Acesso à educação. } \\
\text { Qualidade do ensino. }\end{array}$ & $\begin{array}{l}\text { Aponta decorrências e exigências de uma } \\
\text { gestão democrática a partir do interior da } \\
\text { escola e com fundamento no direito à } \\
\text { educação, tal como dispõe o ordenamento } \\
\text { jurídico sobre o assunto no Brasil. Aborda, } \\
\text { também, temas que vão do acesso à } \\
\text { qualidade à busca da permanência. }\end{array}$ \\
\hline Souza & 2006 & $\begin{array}{l}\text { Gestão escolar. Escola. } \\
\text { Pesquisa em educação. }\end{array}$ & $\begin{array}{l}\text { Faz levantamento bibliográfico da pesquisa } \\
\text { brasileira sobre gestão escolar. No período } \\
\text { de 1981-2001, a partir da análise dos bancos }\end{array}$ \\
\hline
\end{tabular}

Revista Educação e Ciências Sociais, Salvador, v.1, n.1, 2018. 


\begin{tabular}{|c|c|c|c|}
\hline AUTOR & ANO & PALAVRAS-CHAVE & SINTESE DO CONTEÚDO \\
\hline & & & $\begin{array}{l}\text { de dados da ANPEd, CAPES e de um } \\
\text { projeto de pesquisa da PUC-SP, o } \\
\text { levantamento identificou um conjunto de } \\
183 \text { trabalhos de mestrado e doutorado em } \\
\text { educação que examina a problemática da } \\
\text { gestão escolar. }\end{array}$ \\
\hline Ferreira & 2004 & 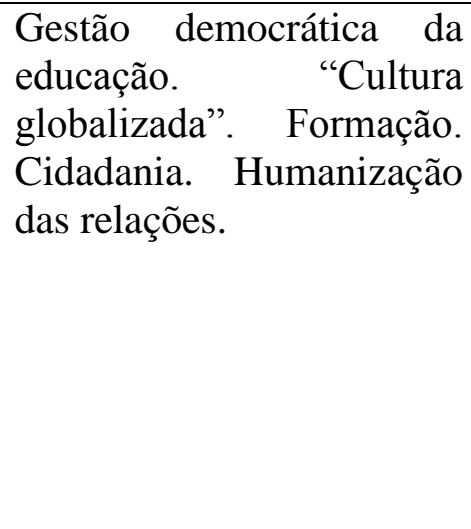 & $\begin{array}{l}\text { Aponta para a necessidade de humanizar a } \\
\text { formação e as condições de existência dos } \\
\text { profissionais da educação e da gestão da } \\
\text { educação ressignificando-as com outra base } \\
\text { ética, que permita fazer frente aos desafios } \\
\text { violentos da "cultura globalizada" na } \\
\text { "sociedade transbordante", "insatisfeita" e } \\
\text { "excludente", "ronstituída } \\
\text { "ressentimentos" e de exacerbação do } \\
\text { individualismo rumo à formação da } \\
\text { cidadania plena. }\end{array}$ \\
\hline Cury & 2002 & $\begin{array}{lrr}\text { Gestão } & \text { e } & \text { democracia. } \\
\text { Gestão. } & \text { Democracia e } \\
\text { educação. } & \text { Gestão } \\
\text { democrática na escola. }\end{array}$ & $\begin{array}{l}\text { Evidencia as bases legais e indica o sentido } \\
\text { mais profundo do princípio da gestão } \\
\text { democrática. }\end{array}$ \\
\hline Libâneo & 2001 & $\begin{array}{lr}\text { Concepções } & \text { de } \\
\text { organização e } & \text { gestão } \\
\text { escolar. } & \text { Estrutura } \\
\text { organizacional da escola. } & \text { da } \\
\begin{array}{l}\text { Elementos constitutivos } \\
\text { do }\end{array} & \text { processo } \\
\text { organizacional. } & \end{array}$ & $\begin{array}{l}\text { São apresentados alguns elementos básicos } \\
\text { para o conhecimento da organização escolar } \\
\text { e para a atuação dos professores e do } \\
\text { pessoal técnico-administrativo. Serão } \\
\text { abordados os seguintes itens: as concepções } \\
\text { de organização e gestão escolar; a estrutura } \\
\text { organizacional da escola; os elementos } \\
\text { constitutivos do processo organizacional. }\end{array}$ \\
\hline Witmann & 2000 & $\begin{array}{l}\text { Autonomia da } r \text { escola. } \\
\text { Democratização. } \\
\text { Demandas para o gestor. }\end{array}$ & $\begin{array}{l}\text { Analisa os fundamentos e as bases do } \\
\text { avanço no pensar e no fazer pedagógico da } \\
\text { educação, apontando as competências } \\
\text { necessárias para que o gestor desempenhe } \\
\text { bem seu trabalho.. }\end{array}$ \\
\hline $\begin{array}{l}\text { Cabral } \\
\text { Neto; } \\
\text { Almeida. }\end{array}$ & 2000 & $\begin{array}{lr}\text { Educação. } & \text { Gestão } \\
\text { descentralizada. } & \text { Conselho } \\
\text { escolar. Caixa } & \text { escolar. } \\
\text { Projeto } & \text { político- } \\
\text { pedagógico. } & \end{array}$ & $\begin{array}{l}\text { Analisam a questão da gestão } \\
\text { descentralizada no sistema de educação } \\
\text { básica, a partir do entendimento de que a } \\
\text { descentralização, nesse âmbito, faz parte da } \\
\text { lógica das reformas modernizadoras do } \\
\text { Estado brasileiro. Destacam e exemplificam } \\
\text { o processo, apresentando a experiência do } \\
\text { Rio Grande do Norte, que propõe } \\
\text { descentralizar o seu sistema educacional } \\
\text { pela criação de Centros Escolares, Conselho } \\
\text { Diretor, Caixa Escolar e Projeto Político- } \\
\text { Pedagógico. Os limites e possibilidades } \\
\text { desse processo de democratização são } \\
\text { objetivamente descritos e analisados. }\end{array}$ \\
\hline Ferreira & 2000 & democrática. & Analisa as limitações da ética liberal em \\
\hline
\end{tabular}




\begin{tabular}{|c|c|c|c|}
\hline AUTOR & ANO & PALAVRAS-CHAVE & SINTESE DO CONTEÚDO \\
\hline & & $\begin{array}{l}\text { Educação. } \quad \text { Formação } \\
\text { humana. }\end{array}$ & $\begin{array}{l}\text { relação à gestão democrática, tendo como } \\
\text { finalidade a construção de uma sociedade } \\
\text { mais humana. Ela desenvolve o estudo a } \\
\text { partir dos questionamentos: até que ponto as } \\
\text { políticas públicas e a gestão da educação } \\
\text { têm garantido, concretamente, a todos os } \\
\text { cidadãos, as mesmas oportunidades de } \\
\text { ensino e possibilidades de aprendizado, a } \\
\text { fim de garantir a formação integral } \\
\text { necessária ao homem e à mulher brasileiros, } \\
\text { no sentido de possibilitar-lhes a plena } \\
\text { participação na sociedade como seres que } \\
\text { têm, não só o direito mas as condições } \\
\text { necessárias para decidir sobre os destinos } \\
\text { das instituições, da nação e de suas próprias } \\
\text { vidas? Como podem os homens e as } \\
\text { mulheres que formamos através da } \\
\text { educação "a única área profissional que lida } \\
\text { com a formação humana" viver, no mundo } \\
\text { hodierno, suas existências e sua profissão } \\
\text { criativa e competentemente, sem que a } \\
\text { gestão da complexidade e da incerteza seja } \\
\text { fator de angústia, mas de fascínio pelo } \\
\text { imprevisto? Conclui com a importância do } \\
\text { conhecimento-emancipação. }\end{array}$ \\
\hline Freitas & 2000 & $\begin{array}{l}\text { Políticas públicas. Gestão } \\
\text { democrático-participativa } \\
\text { na escola pública. } \\
\text { Formação da equipe } \\
\text { escolar. Autonomia na } \\
\text { escola. }\end{array}$ & $\begin{array}{l}\text { O artigo inter-relaciona o contexto das } \\
\text { políticas públicas e a descentralização da } \\
\text { administração do sistema educacional e da } \\
\text { escola pública, enfocando os ideais da } \\
\text { gestão democrático-participativa na } \\
\text { educação, além de discutir a implementação } \\
\text { desses ideais na formação de gestores e } \\
\text { equipes escolares, a partir do referido } \\
\text { contexto. O artigo descreve a ação do } \\
\text { Programa Gestão Participativa (PGP), } \\
\text { desenvolvido na Universidade Federal da } \\
\text { Bahia, com o objetivo de promover a } \\
\text { formação de equipes escolares para que } \\
\text { possam assumir a autonomia pedagógica, } \\
\text { financeira e administrativa da escola. } \\
\text { Depoimentos dos participantes do PGP são } \\
\text { apresentados, dos quais se pode depreender } \\
\text { como é realizada a implementação da } \\
\text { gestão participativa naquele contexto. }\end{array}$ \\
\hline
\end{tabular}

Fonte: SANTOS, 2017.

A série cadernos de gestão de autoria de Heloísa Luck é uma indicação de leitura para os principiantes se familiarizarem com a temática. 
Os textos do quadro 03, acima apresentados, subsidiam com pontos importantes para a interpretação de documentos oficiais sobre a gestão escolar. Quais são as concepções e as funções da Gestão Escolar que estão evidenciadas em documentos oficiais que podem ser traduzidas na atuação democrática e participativa? Objetiva-se identificar as concepções, os princípios e os paradigmas presentes nos documentos oficiais e relacioná-los a atuação democrática e participativa. Apresenta a experiência do gestor escolar com várias vertentes das suas atribuições na dinâmica escolar, tais como, gestão de processos, de finanças, de pessoas e pedagógica, levando em consideração os entraves e dificuldades relacionadas com: falta de motivação da equipe escolar, redução de verbas dos programas de financiamento, falta de uma equipe multidisciplinar, problemas relacionados à fragilidade do pedagógico, gerenciamento de muitos sistemas de alimentação de dados, o cotidiano escolar.

\section{Por que estudar Política e Gestão Educacional no curso de licenciatura: exemplificando com as Ciências Biológicas}

Este texto introdutório para os licenciandos do primeiro semestre do curso Licenciatura em Ciências Biológicas que chega a universidade pensando mais na Biologia pela Biologia do que qualquer outra lógica e se depara com o componente curricular: Política e Gestão Educacional. E, indaga: Por que eu tenho que estudar sobre o Estado e as forças no processo de produção do sistema de ensino, sobre a organização e o funcionamento do ensino em seus aspectos administrativos, didáticos e financeiros e os respectivos nexos entre a legislação e os planos de educação na realidade educacional brasileira, sobre a descentralização da gestão escolar?

A resposta simplista seria porque você será professor.

A resposta legalista, porque reza nas Diretrizes Curriculares Nacionais para os Cursos de Ciências Biológicas, CNE/CES 1.301/2001, aprovado em: 06/11/2001, que a modalidade Licenciatura deverá contemplar, além dos conteúdos próprios das Ciências Biológicas, conteúdos nas áreas de Química, Física e da Saúde, para atender ao ensino fundamental e médio. A formação pedagógica, além de suas especificidades, deverá contemplar uma visão geral da educação e dos processos formativos dos educandos. Deverá também enfatizar a instrumentação para o ensino de Ciências no nível fundamental e para o ensino da Biologia, no nível médio.

Para a Licenciatura em Ciências Biológicas serão incluídos, no conjunto dos conteúdos profissionais, os conteúdos da Educação Básica, consideradas as Diretrizes 
Curriculares Nacionais para a formação de professores em nível superior, bem como as Diretrizes Nacionais para a Educação Básica e para o Ensino Médio. E, quem cumprirá essa determinação é o componente curricular Política e Gestão Educacional. Ele contribuirá com interfaces aos componentes curriculares Docência em Ciências: saber científico/saber escolar.

A resposta política, porque é importante considerar o debate sobre a necessidade de melhoria da qualidade na educação, no qual o professor é ponto essencial do processo de construção. A qualidade da educação perpassa pela instituição de um sistema nacional de educação, que responda a formação inicial e continuada do professor. Há, também, uma exigência em analisar as políticas na área de Formação e Trabalho Docente, como são implantadas, vivenciadas e interpretadas em contextos escolares.

Porque dentre as habilidades/competências que deve desenvolver o professor está a de portar-se como educador consciente de seu papel na formação de cidadãos, inclusive na perspectiva socioambiental; de comprometer-se com o desenvolvimento profissional constante, assumindo uma postura de flexibilidade e disponibilidade para mudanças contínuas, esclarecido quanto às opções sindicais e corporativas inerentes ao exercício profissional.

Pensar a Política e Gestão Educacional, em sessenta horas, em um curso de graduação, resultaria em uma divisão de seis eixos temáticos, a saber: O Estado e as forças no processo de produção do sistema de ensino; A organização e o funcionamento do ensino em seus aspectos administrativos, didáticos e financeiros e os respectivos nexos entre a legislação e os planos de educação na realidade educacional brasileira; Diretrizes Curriculares Nacionais Gerais da Educação Básica; Visão panorâmica da gestão pública escolar; Planejamento da escola e o projeto político pedagógico; O professor na sociedade contemporânea: um trabalhador da contradição.

\section{Resultados}

O estudo de Política e Gestão Educacional na licenciatura tem como objetivo geral, analisar o papel do Estado na formulação das políticas educacionais, na organização e no funcionamento do ensino em seus aspectos administrativos, didáticos e financeiros e os respectivos nexos entre a legislação e os planos de educação na realidade educacional brasileira. Bem como, a descentralização da gestão escolar. 
Os seis eixos temáticos mencionados na seção anterior têm várias possibilidades de tradução em um planejamento de ensino, dentre elas a que segue abaixo:

O Estado e as forças no processo de produção do sistema de ensino: Educação escolar no contexto brasileiro: processos e práticas de regulação. O que é educação, natureza e especificidade da educação, modalidades da educação. Trabalho educativo, objeto da educação, papel da escola básica. Concepções de educação, dimensões da educação, sentidos da educação. Os significados da educação, modalidades de prática educativa e a organização do sistema educacional. Estado, escola e família. Projeto de Lei nº 867, de 2015 - "Programa Escola Sem partido". A política e as bases do direito educacional. O Estado, a educação e a regulação das políticas públicas. Estado e políticas (públicas) sociais. Políticas públicas educacionais: revisão histórica.

A organização e o funcionamento do ensino em seus aspectos administrativos, didáticos e financeiros e os respectivos nexos entre a legislação e os planos de educação na realidade educacional brasileira: Os planos, as diretrizes e a legislação para a educação básica. Constituição Federal de 1988; LDB 9394/96. Sistema Nacional de Educação e Plano Nacional de Educação. Lei no 11.274/2006, que institui a ampliação do tempo de duração do ensino fundamental de oito para nove anos. A Lei $\mathrm{n}^{\mathrm{o}} 13.005$, de 25 de junho de 2014 que institui o Plano Nacional de Educação (PNE) para o período de 2014-2024.

Para aprofundar o estudo sobre Sistema Nacional de Educação e o Plano Nacional de Educação a indicação é o livro de SAVIANI (2014) - Sistema Nacional de Educação e Plano Nacional de Educação: significado, controvérsias e perspectivas.

Diretrizes Curriculares Nacionais Gerais da Educação Básica: Diretrizes Nacionais para Educação Infantil. Diretrizes Curriculares da Educação de Jovens e Adultos. Diretrizes Curriculares Nacionais para a Educação Profissional Técnica de Nível Médio. Diretrizes da Educação Especial. Diretrizes Operacionais para Educação Básica nas Escolas do Campo. Diretrizes para a Politica da Educação Indígena. Diretrizes para Ensino Fundamental de Nove Anos. Diretrizes e Resolução da Educação Escolar Quilombola. Diretrizes Curriculares Nacionais para Educação das Relações Étnico Raciais e para o Ensino de História e Cultura Afro-Brasileira e Africana. Diretrizes Curriculares Nacionais para a Educação em Direitos Humanos. Diretrizes Curriculares Nacionais para a Educação Ambiental.

Recomendamos a leitura de BRASIL. Diretrizes Curriculares Nacionais Gerais da Educação Básica, 2013. 
Visão panorâmica da gestão pública escolar: o que é uma gestão pública; quem e como administra a Unidade Escolar. Organização e gestão do sistema escolar: aspectos pedagógicos, administrativos e financeiros. Descentralização da gestão escolar.

Planejamento da escola e o projeto político pedagógico

[...] O Projeto Político Pedagógico (PPP) visa nortear a prática pedagógica das unidades escolares, o aprimoramento de ensino-aprendizagem dos estudantes garantindo o acesso e a permanência desses na escola, evitando a evasão e o abandono escolar.

No Projeto Político Pedagógico (PPP) os conteúdos devem ser adequados à prática pedagógica, à condição de desenvolvimento e aprendizagem dos estudantes, às configurações culturais de cada escola, a ampliação de conhecimento dos estudantes ao final de cada ano letivo. [...] (SANTOS; SANTOS; SILVA, 2009, p. 16)

Recomendamos a leitura de Veiga (2002) sobre projeto político pedagógico. E, a consulta ao livro Federalismo e políticas educacionais na efetivação do direito à educação no Brasil, por trazer vários artigos em que a questão do financiamento da educação está presente.

O professor na sociedade contemporânea, recomendamos a leitura da Resolução $\mathrm{n}^{\mathrm{o}} 2$, de $1^{\mathrm{o}}$ de julho de 2015, do artigo de Charlot (2008) e dos livros Guimarães (2005), Ramalho; Nunez; Gauthier (2004), Freire (2001, 1987, 1987, 1981), Barzano e Araujo (orgs.) (2011), Santos (2012).

Para dar conta do conteúdo é interessante uma proposta de planejamento de ensino com atividades de exposição dialogada, leitura crítica dos textos e da realidade, debate, roda de conversa, júri simulado, caça tesouro, simpósio, mesa redonda, oficina pedagógica.

\section{Considerações finais}

Perspectivas teóricas opostas têm permeado a concepção das políticas atuais. Dentre as possibilidades de se trabalhar com Política e Gestão Educacional deve-se perguntar sempre, qual é o meu papel de cidadão na vida política e pública na sociedade?

\section{Referências}

ALVES, Luciana; BATISTA, Antônio Augusto Gomes; RIBEIRO, Vanda Mendes; ÉRNICA, Maurício. Seleção velada em escolas públicas: práticas, processos e princípios geradores. In: Educação e Pesquisa, São Paulo, v. 41, n. 1, p. 137-152, jan./mar. 2015. 
Disponível em: 〈www.scielo.br/pdf/ep/v41n1/1517-9702-ep-41-1-0137.pdf>. Acesso em: 18 abr. 2017.

AZEVEDO, Janete Maria Lins de. O projeto político-pedagógico no contexto da gestão escolar. Escola de gestores da educação básica. Disponível em: www.tvbrasil.com/salto. Acesso em: 21 nov. 2017.

BARROSO, João. O estado, a educação e a regulação das políticas públicas. In: Educação e Sociedade. Campinas, v. 26, n. 92, p. 725-751, Especial - out. 2005. Disponível em: www.scielo.br/pdf/es/v26n92/v26n92a02.pdf.

BARZANO, Marco Antonio Leandro; ARAUJO, $\mathrm{M}^{\mathrm{a}}$ de Lourdes Haywanon (orgs.). Formação de professores: retalhos de saberes. Feira de Santana: UEFS Editora, 2011.

BRANDÃO, Carlos. O que é educação. São Paulo: Brasiliense, 1981. (Coleção primeiros passos)

BRASIL, Constituição da República Federativa do Brasil. São Paulo: Saraiva, 1998.

BRASIL, Lei no 9.394 de dezembro de 1996. Estabelece a Lei de Diretrizes e Bases da Educação Nacional. 5 ed. Brasília, DF: Câmara dos Deputados, 2010.

BRASIL. Resolução $\mathbf{n}^{0}$ 2, de $1^{\circ}$ de julho de 2015. Define Diretrizes Curriculares Nacionais para a formação inicial em nível superior (cursos de licenciatura, cursos de formação pedagógica para graduados e cursos de segunda licenciatura) e para a formação continuada. Diário Oficial da União, Brasília, 2 de julho de 2010, Seção 1, p. 8 12.

BRASIL. Lei no 13.005, de 25 de junho de 2014 (Plano Nacional de Educação (PNE) 2014-2024). Disponível em www.observatoriodopne.org.br/uploads/.../documentoreferencia.pdf.

BRASIL. Ministério da Educação. Secretaria de Educação básica. Secretaria de Educação Continuada, Alfabetização, Diversidade e Inclusão. Secretaria de Educação Profissional e Tecnológica. Conselho Nacional de Educação. Câmara Nacional de Educação Básica. Diretrizes Curriculares Nacionais Gerais da Educação Básica. Brasília: MEC, SEB, DICEI, 2013.

BRASIL. Projeto de Lei no 867, de 2015. Disponível em: http://www.adufrj.org.br/tireamao/wp-content/uploads/2016/06/PL867-2015.pdf.

BRZENZINSKI, Iria (org). LDB dez anos depois: reinterpretação sob diversos olhares. São Paulo: Cortez, 2008.

CABRAL NETO, Antônio; ALMEIDA, Maria Doninha de. Educação e gestão descentralizada: conselho escolar, caixa escolar e projeto político-pedagógico. In: Em Aberto, Brasília, v. 17, n. 72, p. 35-46, fev./jun. 2000.

CASTRO, Jorge Abrahão de. Financiamento da educação no Brasil. In: Em aberto, v. 18, n. 74, p. 11-32, dez. 2001. 
CAVALCANTE, Ailton Ferreira. Ensino público: gratuito, em termos - custos indiretos do ensino médio para os alunos das escolas públicas do Distrito Federal. In: Em Aberto, Brasília, v. 19, n. 75, p. 113-122, jul. 2002.

CHARLOT, Bernard. A pesquisa educacional entre conhecimentos, políticas e práticas: especificidades e desafios de um área do saber. In: Revista Brasileira de Educação, v. 11, n. 31, p. 7-18, jan./abr. 2006. Disponível em: http://www.scielo.br/pdf/rbedu/v11n31/a02v11n31.pdf

CHARLOT, Bernard. O professor na sociedade contemporânea: um trabalhador da contradição. In: Revista da FAEEBA - Educação e Contemporaneidade, Salvador, v. 17, n. 30, p. 17-31, jul./dez., 2008.

COSTA, Gilvan Luiz Machado; OLIVEIRA, Dalila Andrade. O trabalho docente no ensino médio no Brasil: sujeitos e condições singulares. In: GOUVEIA, Andréa Barbosa; PINTO, José Marcelino Rezende; CORBUCCI, Paulo Roberto (orgs.). Federalismo e políticas educacionais na efetivação do direito à educação no Brasil, Brasília: Ipea, 2011, p. 151171.

CRUZ, Rosana Evangelista da. Federalismo e financiamento da educação: a política do FNDE em debate. In: GOUVEIA, Andréa Barbosa; PINTO, José Marcelino Rezende; CORBUCCI, Paulo Roberto (orgs.). Federalismo e políticas educacionais na efetivação do direito à educação no Brasil, Brasília: Ipea, 2011, p. 79-84.

CURY, Carlos Roberto Jamil. A educação básica como direito. Cadernos de Pesquisa [online]. 2008, v. 38, n. 134, p. 293-303, maio/ago. 2008. ISSN 0100-1574. Disponível em: http://dx.doi.org/10.1590/S0100-15742008000200002. Acesso em: 22 mar. 2017.

CURY, Carlos Roberto Jamil. A Gestão Democrática e o direito à educação. Revista Brasileira de Política e Administração da Educação ANPAE. Porto Alegre, v. 23, n. 3, p. 483- 495, set./dez., 2007.

CURY, Carlos Roberto Jamil. A gestão democrática na escola e o direito à educação. RBPAE. v. 23, n. 3, p. 483-495, set./dez. 2007.

CURY, Carlos Roberto Jamil. Gestão democrática da educação: exigências e desafios. RBPAE. v. 18, n. 2, p. 163-174, jul./dez. 2002.

DAVIES. Nicholas. FUNDEB: a redenção da educação básica? In: Educação e Sociedade. v. 27, n. 96 - Especial, p. 753 - 774, out. 2006. Disponível em <http://www.cedes.unicamp.br>

DUARTE, Clarice Seixas. Direito público subjetivo e políticas educacionais. In: São Paulo em perspectiva, 18 (2), p. 113-118, 2004.

Em aberto - gestão educacional e formação de gestores. Brasília, v. 19, n. 72, fev./jun. 2000 .

Em aberto - gestão educacional: o Brasil no mundo contemporâneo. Brasília, v. 19, n. 75, jul. 2002. 
FARENZENA, Nalu. Políticas de assistência financeira da união no marco das responsabilidades (inter) governamentais em educação básica. In: GOUVEIA, Andréa Barbosa; PINTO, José Marcelino Rezende; CORBUCCI, Paulo Roberto (orgs.). Federalismo e políticas educacionais na efetivação do direito à educação no Brasil, Brasília: Ipea, 2011, p. 95-110.

Federalismo e políticas educacionais na efetivação do direito à educação no Brasil./ organizadores: André Barbosa Gouveia, José Marcelino Rezende Pinto, Paulo Roberto Corbucci. Brasília: Ipea, 2011.

FERREIRA, Naura Syria Carapeto. Gestão democrática da educação para uma formação humana: conceitos e possibilidades. In: Em Aberto, Brasília, v. 17, n. 72, p. 167-177, fev./jun. 2000.

FERREIRA, Naura Syria Carapeto. Repensando e ressignificando a gestão democrática da educação na "cultura globalizada". In: Educação e Sociedade, Campinas. v. 25, n. 89, p. 1227-1249, set/dez. 2004. Disponível em <http:// www.cedes.unicamp.br〉.

FREIRE, P. Pedagogia da autonomia: saberes necessários à prática educativa. 6 ed. São Paulo: Paz e Terra, 1997. 165 p.

FREIRE, P; SHOR, Ira. Medo e ousadia: o cotidiano do professor. Rio de Janeiro: Paz e Terra, 1987. $116 \mathrm{p}$.

FREIRE, Paulo. "Considerações em torno do ato de estudar". FREIRE, Paulo. Ação cultural para liberdade e outros escritos. 5 ed. Rio de Janeiro: Paz e Terra, 1981. p. 8-10. (O Mundo, Hoje, v. 10)

FREIRE, Paulo. Educação e responsabilidade. In: FREIRE, Paulo. Política e educação. 5 ed. São Paulo: Cortez, 2001. p. 44-46.

FREIRE, Paulo. Política e educação: ensaios. 5 ed. São Paulo: Cortez, 2001. 57p. (Coleção questões de nossa época, v. 23)

FREITAS, Katia Siqueira de. Uma Inter-relação: políticas públicas, gestão democráticoparticipativa na escola pública e formação da equipe escolar. In: Em Aberto, Brasília, v. 17, n. 72, p. 47-59, fev./jun. 2000.

GUIMARÃES, Valter Soares. Formação de professores: saberes, identidade e profissão. 2 ed. Campinas, SP: Papirus, 2005

HOFLING, Eloisa de Mattos. Estado e políticas (públicas) sociais. In: Cadernos Cedes, ano XXI, n. 55, p. 30-41, nov. 2001.

LIBÂNEO, José Carlos. "O sistema de organização e gestão da escola" In: LIBÂNEO, José Carlos. Organização e gestão da escola: teoria e prática. Goiânia: Alternativa, 2001. Disponível em: <http://www.acervodigital.unesp.br/bitstream/123456789/32/3/LDB_Gest\%C3\%A3o.pdf>. Acesso em: 02 jun. 2016. 
LIBÂNEO, José Carlos. OLIVEIRA, João Ferreira de T. et al. Educação escolar: políticas, estrutura e organização. São Paulo: Cortez, 2008.

LIBÂNEO, José Carlos. Os significados da educação, modalidades de prática educativa e a organização do sistema educacional. In: LIBÂNEO, José Carlos. Pedagogia e pedagogos para quê? 12 ed. 3 reimpr. São Paulo: Cortez, 2013.

LIBÂNEO, José Carlos; OLIVEIRA, José Ferreira de; TOSCHI, Mirza Seabra. Educação escolar: políticas, estrutura e organização. São Paulo: Cortez, 2009.

LIMA, Antonio Bosco de. Estado, escola e família: sobre o direito de escolha. In: Educare et educare - revista de educação, v. 3, n. 6, p. 87-99, jul./dez. 2008.

LUCK, Heloísa. A Gestão participativa na escola. 10 ed. Petrópolis, RJ: Vozes, 2011. Série Cadernos de Gestão.

LUCK, Heloísa. Concepções e processos democráticos de gestão educacional. 9 ed. Petrópolis, RJ: Vozes, 2013.

LUCK, Heloísa. Gestão da cultura e do clima organizacional da escola. Petrópolis, RJ: Vozes, 2010. Série Cadernos de Gestão.

LUCK, Heloísa. Gestão educacional: uma questão paradigmática. 9 ed. Petrópolis, RJ: Vozes, 2011. (Série cadernos de gestão).

LUCK, Heloísa. Liderança em gestão escolar. 4 ed. Petrópolis, RJ: Vozes, 2010. Série Cadernos de Gestão.

LUCK, Heloísa. Perspectivas da avaliação institucional da escola. Petrópolis, RJ: Vozes, 2012. Série Cadernos de Gestão.

LÜCK, H. et al. A escola participativa: o trabalho do gestor escolar. 2 ed. Rio de Janeiro: DP\&A, 1998.

MITTER, Wolfgang. A educação no Processo de Globalização: algumas considerações sobre um debate atual e controverso. In: Em aberto, Brasília, v. 19, n. 75, p. 23-34, jul. 2002 .

OLIVEIRA, Adão Francisco de. Políticas públicas educacionais: conceito e contextualização numa perspectiva didática. Disponível em: http://www.aedmoodle.ufpa.br. Acesso em: 05 mar. 2017.

RAMALHO, Betania Leite; NUNEZ, Isauro Beltrán; GAUTHIER, Clermont. Formar o professor, profissionalizar o ensino: perspectivas e desafios. 2 ed. Porto Alegre: Sulina, 2004.

SANTOS, Ana Lúcia Félix dos; AZEVEDO, Janete Maria Lins de. O GT 05 - Estado e política educacional - no contexto do Encontro de Pesquisa Educacional do Norte e Nordeste: um olhar sobre sua produção. In: GOMES, Alfredo Macedo; LEAL, Telma 
Ferraz. Pesquisas em educação nas regiões norte e nordeste: balanço e perspectivas. Recife: Editora UFPE, 2014.

SANTOS, Cristiano dos; SANTOS, Selma dos; SILVA, Irlana Jane Menas da (org). Mentes e mãos construindo o Projeto Político Pedagógico (PPP). Feira de Santana: Universidade Estadual de Feira de Santana, 2009.

SANTOS, Selma dos; et al. Novas demandas de formação profissional docente no município de Santo Estêvão - Bahia - Brasil. Revista Metáfora Educacional (ISSN 1809-2705) versão online. Editora Dra. Valdeci dos Santos. Feira de Santana - Bahia (Brasil), n. 20 (jan. - jun. 2016), 25 jun. 2016, p. 3-42. Disponível em: <http://www.valdeci.bio.br/revista.html>. Acesso em: 20 nov. 2017.

SANTOS, Valdecí dos. Memórias de uma professora-bióloga: desejos, olhares e espelhos. Feira de Santana, s. n., 2012.

SAVIANI, Dermeval. Organização da educação nacional: sistema e conselho nacional de educação, plano e fórum nacional. In: Educação e Sociedade, Campinas, v. 31, n. 112, p. 769-787, jul./set. 2010.

SAVIANI, Dermeval. Política educacional brasileira: limites e possibilidades. In: Revista de Educação PUC Campinas, Campinas, n. 24, p. 7-16, jun. 2008 a.

SAVIANI, Dermeval. Sistema Nacional de Educação e Plano Nacional de Educação: significado, controvérsias e perspectivas. Campinas, SP: Autores Associados, 2014. 117 p. (Coleção polêmicas do nosso tempo)

SAVIANI, Dermeval. Sobre a natureza e especificidade da educação. In: SAVIANI, Dermeval. Pedagogia histórico-crítica: primeiras aproximações. 10 ed. rev. Campinas: Autores Associados, 2008b. (Coleção educação contemporânea)

SILVA, Antonia Almeida; JACOMINI, Márcia Aparecida. Pesquisas em educação e em políticas educacionais: das apostas epistemológicas à construção do campo. In: SILVA, Antonia Almeida; JACOMINI, Márcia Aparecida (org.). Pesquisas em políticas educacionais: características e tendências. Feira de Santana: UEFS Editora, 2016. p. 33-61.

SOUZA, Ângelo Ricardo de. A política educacional e seus objetos de estudo. In: Revista de Estudos Teóricos y Epistemológicos em Politica Educativa, v. 1, n. 1, p. 75-89, enerojunio, 2016.

SOUZA, Ângelo Ricardo de. A produção do conhecimento e o ensino da gestão educacional no Brasil. In: RBPAE, v. 24, n. 1, p. 51-60, jan./abr. 2008.

SOUZA, Ângelo Ricardo de. Os caminhos da produção científica sobre gestão escolar no Brasil. RBPAE, v. 22, n. 1, p. 13-39, jan./jun. 2006.

SOUZA, Celina. Políticas públicas: questões temáticas e de pesquisas. Caderno CRH, Salvador, v. 16, n. 39, p. 11-24, 2003. 
SOUZA, Celina. Políticas Públicas: uma revisão da literatura. Sociologias, Porto Alegre, ano 8, n. 16, p. 20-45, jul./dez. 2006.

VEIGA, Ilma Passos Alencastro (org.) Projeto político pedagógico da escola: uma construção possível. 15 ed. Campinas, SP: Papirus, 2002.

VIEIRA, Evaldo. A política e as bases do direito educacional. In: Cadernos Cedes, ano XXI, n. 55, p. 9-29, novembro/2001. Disponível em: http://www.scielo.br/pdf/ccedes/v21n55/5538

VIEIRA, Sofia Lerche. Política (s) e gestão da educação básica: revisitando conceitos simples. Revista Brasileira de Política e Administração da Educação. Rio de Janeiro, v. 23. n. 1, p.53-69, jan./abr. 2007. Disponível em: www.seer.ufrgs.br/rbpae/article/download/19013/11044.

WEBER, Silke. O plano nacional de educação e a valorização docente: confluência do debate nacional. Cadernos Cedes, Campinas, v. 35, n. 97, p. 495-515, set./dez., 2015.

WITMANN, Lauro Carlos. Autonomia da escola e democratização de sua gestão: novas demandas para o gestor. Em Aberto, Brasília, v. 17, n. 72, p. 88-96, fev./jun. 2000. 